\title{
An Intelligent Marketspace Mobile Application for Marketing Organic Products
}

\author{
Oluwasefunmi 'Tale Arogundade ${ }^{1(\bowtie)}(\mathbb{D})$, Adebayo Abayomi-Alli ${ }^{1}(\mathrm{D})$, \\ Kayode Adesemowo ${ }^{2}$ (D), Taiwo Bamigbade ${ }^{1}$, Modupe Odusami ${ }^{3}$ (D), \\ and Victor Olowe ${ }^{1}$ \\ ${ }^{1}$ Federal University of Agriculture, Abeokuta, Nigeria \\ \{arogundadeot, abayomiallia,olowevio\}@funaab.edu.ng, \\ bamigbadetaiwo@gmail.com \\ 2 Nelson Mandela University, Port Elizabeth, South Africa \\ kadesemowo@soams.co.za \\ 3 Covenant University, Ota, Nigeria \\ modupe. odusami@convenantuniversity.edu.ng
}

\begin{abstract}
Sustainable food security (Sfs) desires not only that people always have passage to ample and nutritious food, but also that this food be formed with minimum environmental impact. This research is aimed at developing a mobile application for marketing organic farm products with the functionality of automated geo-location services, preferred goods delivery services, easy access to different organic farm produce. The mobile user platform consists of the Presentation, Business, Data and Data storage which is a slight variation of the Model-View-Controller architecture. It also takes into deep awareness the configuration, security and communications aspect as these are the underlying factors for the robustness of mobile application. The Presentation Tier consists of the user interface and the logic used to navigate around the user interface meaningfully. It modifies and shows information into a human distinct pattern. The Business Logic tier is essentially efficient for information transfer between the user interface and the database of the project. The last layer of the threetiered architecture is the Data Access tier, which is made up of the Database servers. The application was implemented in Java, SQLite (local) and PHP for the backend server and Amazon Web Services for cloud infrastructure. Farmers were engaged in cursory testing. Users find the application concept very interesting.
\end{abstract}

Keywords: Access $\cdot$ Geolocation $\cdot$ Marketspace $\cdot$ Model view $\cdot$ Orgafamob · Organic farming $\cdot$ Pragmatism $\cdot$ Sustainable food

\section{Introduction}

Agriculture is the main factor for the survival of humans and it also provides food, fuel and other services in line with ecosystems. It plays an important function in economic development and it is an essential source of livelihood. Agriculture is also a crucial origin of environmental downgrading, adding to climate variation, decreasing freshwater resources, detracting soil fertility and contaminating the environment over 
fertilizer and pesticide [1, 2]. Essentially, food production relies on the lofty natural resources it is derogating. Sfs therefore not only requires that all people always have access to sufficient and nutritious food, but food be formed with minimal environmental brunt. Hence, sustainable agricultural development desires that agriculture face the demands of the present without negotiating the capability of future generations to tourney their own demands [3]. Achieving these goals by current Agriculture practices has not been very successful. Today, Agriculture is not only a dominating factor of environmental degradation, it is a major force compelling the Earth System beyond the 'safe-operating space' for humanity [4, 5].

Knowing that we have not achieve Sf s today and given the fact that we will probably need to double food production by 2050 so that we can feed 9 billion people with rising demand for meat and dairy products [6], there is a drastic need for changes in the food system. We need to increase the production of food in the right locations at fair prices, protecting livelihoods to farmers and reducing the environmental cost of agriculture. Recently, the market for organic food (ORF) has increased, and call for fair sustainable farming.

It is worth mentioning that this research is aimed at developing a mobile application for marketing organic farm products with the functionality of automated geo-location services, preferred goods delivery services, easy access to different organic farm produce. Although a considerable amount of study can be found in the literature which identifies the attitude of dairy farmers towards organic farming [7, 8], economic and social implications of organic agriculture [9], these did not take mobile and real-time, geo-location into due consideration. The contributions of this work are:

- Ensuring real time information delivery on changing trends and key discoveries in the organic farm produce.

- Providing organic farmers cultivating crops with an e-commerce platform for easy facilitation of their business.

- Enabling practicing organic farmers form a cluster around themselves thereby empowering them with the benefits that comes with economics of scale.

The paper is organized in the following way. Section 2 comprises of related works in the area of organic farming and mobile applications that has been developed to improve the availability of organic products. Section 3 deals with the requirement analysis and design methodology of the proposed mobile application. In Sect. 4, we detail the implementation of the mobile application for organic market Space. Finally, Sect. 5 includes our conclusion.

\section{Literature Review and Related Works}

In this section, we discuss the economic and social meanings of organic Agriculture, and the usage of ICT and mobile technology in Agriculture. 


\subsection{Economic and Social Implications of Organic Agriculture (OA)}

The advantage of OA for micro farmers is reliant on organic yields, the cost of organic production, and the size of the organic price choice [10]. In [11], economic impact of organic farming in livelihoods of farmers of Nepal was explored. Binta and Barbier in [2], carried out a comparative study on the economic and environmental performances of organic and conventional horticultural farming systems in the Niayes region in Senegal.

Health has been one of the major reasons consumers purchase organic goods $[12,13]$ so much as safety, quality and taste [14-17] are very imperative motivations for purchasing ORF. In marketing and promoting organic ORF, eating pleasure (particularly tastiness) is now the main argument, followed by health and then environmental benefits $[18,19]$. It is surprising to discover that consumers appear to be relatively incognizant of the constructive impact that OA has on the environment [20].

Results showed that economically, farmers were found satisfied and encouraged to expand their organic business. Although, there is limited market for ORF in the region unlike the conventional farming however, investment in agro-ecological research, organic management can greatly improve it. Especially through the establishment of a local market for organic crops. Hence, [21] explained that the study put out by the Maine Organic Farmers and Gardeners Association (MOFGA) indicates that these farms are contributing to Maine's economy positively.

\subsection{ICT and Mobile Technology in Agriculture}

A short introduction of the implications of ICTs in agricultural sector was presented in [22]. The authors demonstrated the fact that there are large number of ICT-enabled services which can improve many processes in the agricultural sector. In [23] the impact of proliferation of ICTs was investigated, due to the growth of mobile technologies, in order to know if it has actually had any significant impact on Agriculture. It was confirmed that ICTs play a significant role in enhancing agricultural production. Study [24] presented a research that assessed the traits, diversity and impacts of ICTs used in African agriculture. The key challenges hindering more widespread use of the technologies were also highlighted by the author. The study in [24], vividly reveals that ICTs are making impact in increasing productivity and marketing of products but there are still several constraints for adequate utilization by the farmers. Hence, there is likelihood that combination of mobile technologies with other ICT platforms such as mass media, will have exponential impact on agriculture. Study in [25] on the influence of ICT in agriculture, (in developing countries), in respect of opportunities and challenges, found that one of the major benefits of ICT in agricultural sector is the improvement of market activities.

Finally, it is merit observing that the motivation of buyers to buy ORF are interest and sentimental federation of organic goods with realness and reminiscence taste of the past. However, the loss of adequate provision of ORF [18] and, above all, its higher 
price is often a strong obstacle to the purchase of ORF. Also, the inadequacy of information on the meaning of ORF [26], coupled with diverse of ways to label organic products has affected the purchasing power of organic products. Despite the fact that organic farming looks quite comforting for consumers, the response of farmers to the concept is not at an alarming rate. Only a minority of farmers, especially in dairy areas, are in favour of organic farming.

\section{Methodology}

The Orgfarmob, is underpinned by pragmatism philosophy as it seeks to provide practical solutions and outcomes [27]. It follows the build and process methods from a design research point of view [28, 29], rather than design science research methodology strategy. Given the emphasis on practical solutions, the logical design, presented as the design process, is the primary focus of this paper: the development of orgfarmob marketspace. It starts off tilting towards inductive approach to discern better the nature of the problem within the context (organic farmers in Nigeria) and guide towards gathering requirement [27].

Before proceeding with 'requirement analysis', 'architectural framework' and 'design and use-case design considerations', we quickly outline the orgfarmob marketspace build and process approach. In line with our pragmatic approach, we built on aspects of the framework for computing research methods [29]. We only utilized aspects that we required and applicable to our study. The following were considered:

\subsection{Framework for Computing Research}

- What do we want to achieve?

a. (Find out what is happening) - the authors wished to achieve a better understanding of the use and application of ICT mobile development in organic farming (in Nigeria), starting with the western part of Nigeria.

b. (Develop something that works) - the authors will embark on developing a mobile tool, orgfarmob' to understudy and assist organic farmers.

- Where did the data come from?

c. (Read) - the authors will literatures on organic farming and ICT in agriculture.

d. (Observe, Ask) - the authors will engage with and get opinions from organic farming practitioners in western part of Nigeria.

e. (Model) - the authors will conceptualise and utilize UML to model practical design model covering user activity, admin activity, entity- relationship and sequence.

f. (Where to collect) - the authors will collect and collate relevant requirement and design data from the field and conceptual analysis. 
- What did they do with the data?

g. (Identify themes, Identify trends) - the authors will use the collated information to better understand organic farming and use of ICT in organic farming.

h. (Create frameworks/taxonomy/prototype) - the authors will in the first iteration design an architectural framework for orgfarmob. Thereafter, in iterative manner, the author will prototype the orgfarmob application.

- Had they achieved their goal?

i. (Evaluate results, Draw conclusions) - the authors, having gain understanding and developed working prototype, will now be better placed to analyse and iteratively finetune the design and build (soft- ware development).

j. (identify limitation) - the authors will draw from the design and development process what are the bounds of limits and/or how prior studies can be extended or critique.

Flowing from the framework for computing research approach, this study was carried out through source of opinions from organic agriculture practitioners, some web materials, survey of organic farmers in Nigeria and the world at large through the internet and personal interview of organic farming practitioner.

The Unified Modelling Language (UML), Meta model elements are arranged diagrammatically. Several diagrams are used for distinct purpose based on the angle from which you are viewing the system. The various views are called "architectural views". These architectural views enable the organization of knowledge, and diagrams allow the communication of knowledge. Then knowledge itself is contained in the model or set of models that focuses on the problem and solution. Figure 1 depicts the architectural view of the proposed study. The given implementation model is majorly categorized into two broad categories which are the mobile user platform and the remote infrastructure.

\subsection{Architectural Framework}

The mobile user platform consists of the Presentation, Business, Data and Data storage which is a slight variation of the Model-View-Controller architecture. It also takes into deep awareness the configuration, security and communications aspect as this are the underlying factors for the robustness of the mobile application. The Presentation Tier consists of the user interface and the logic used to navigate around the user interface meaningfully. It converts and displays information into a human legible form. The Business Logic tier is mainly responsible for information exchange between the user interface and the database of the project. 
The last layer of the three-tiered architecture is the Data Access tier, which consists of the Database servers. The updates of the information and server communication exist here.

\subsection{Design and Use-Case Design Considerations}

In line with the pragmatic approach of this paper, the logical design is the critical and main design process [30]. The software coding thereafter results in the developed prototype which is the first instance of validation of the design process.

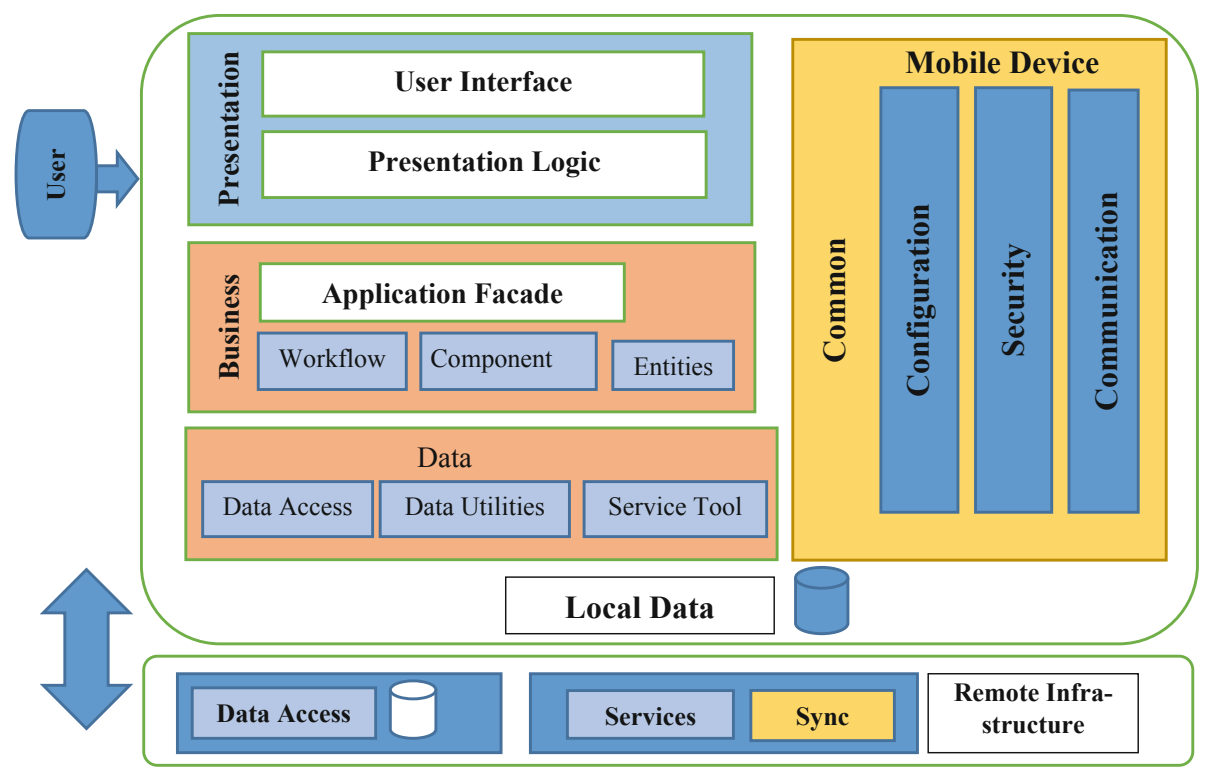

Fig. 1. Standard system architecture for mobile application development

Figure 2 depicts the User Activity Diagram and the Admin Activity Diagram of the proposed study is shown in Fig. 3.

Activity diagram, an important diagram in UML, was used to conceptualised and express driving aspects of the system. It is essentially a flowchart that depict the flow from one activity to another. 


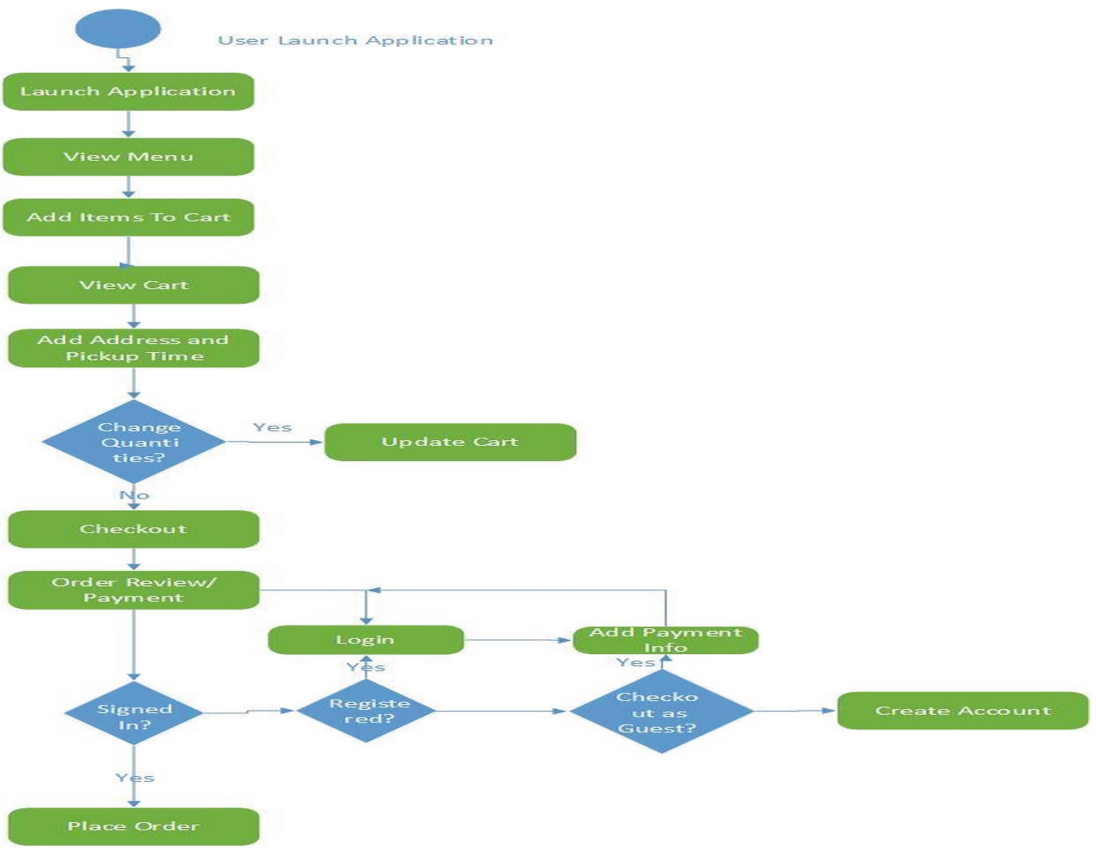

Fig. 2. User Activity Diagram

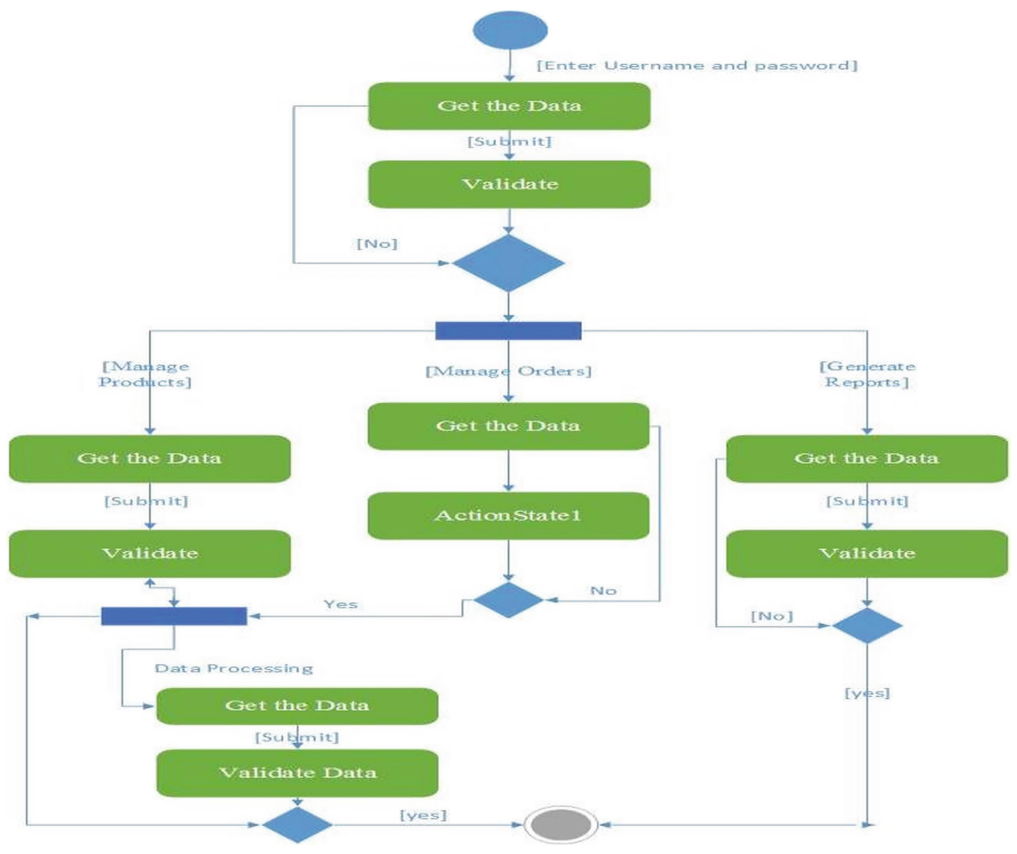

Fig. 3. Admin Activity Diagram 


\subsection{Entity Relationship and Sequence Diagram}

The Entity-Relationship Diagram (ERD) shows the relationships of entity sets stored in a database as depicted in Fig. 4.

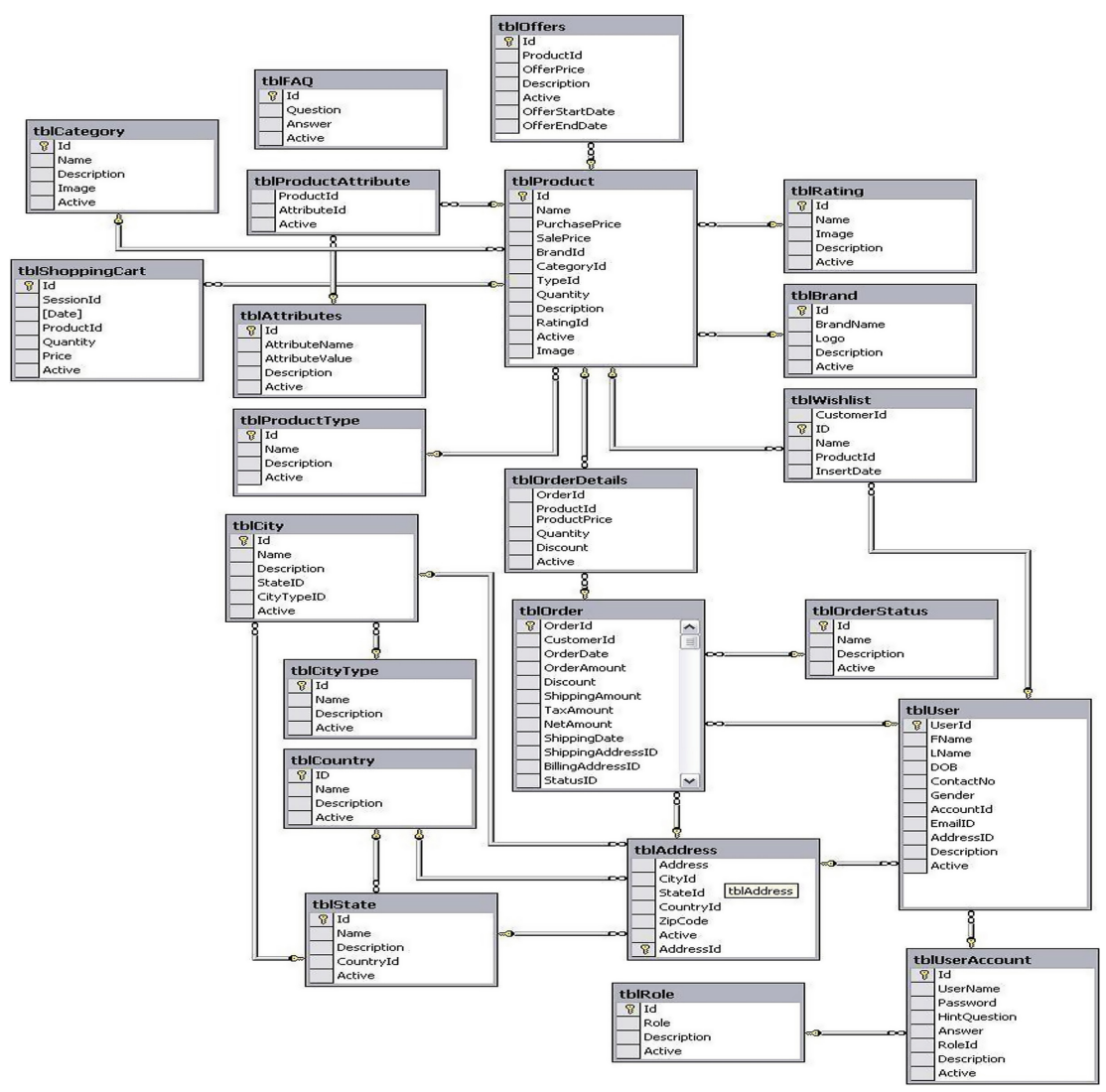

Fig. 4. Entity-Relationship Diagram

Sequence diagrams, also called event diagrams, with only one instance shown in Fig. 5, describe interactions among classes in terms of an exchange of messages over time. Due to space constraint, we couldn't show the sequence diagrams for each of the interactions and communications between the entities involved in the system.

\section{Results and Discussion}

In this section, we only discuss some of the modules incorporated into the mobile application to achieve the objectives of this research work. The result thus far, which flows from the framework for computing research and use-case approaches is a web and mobile application management system for organic farming. 


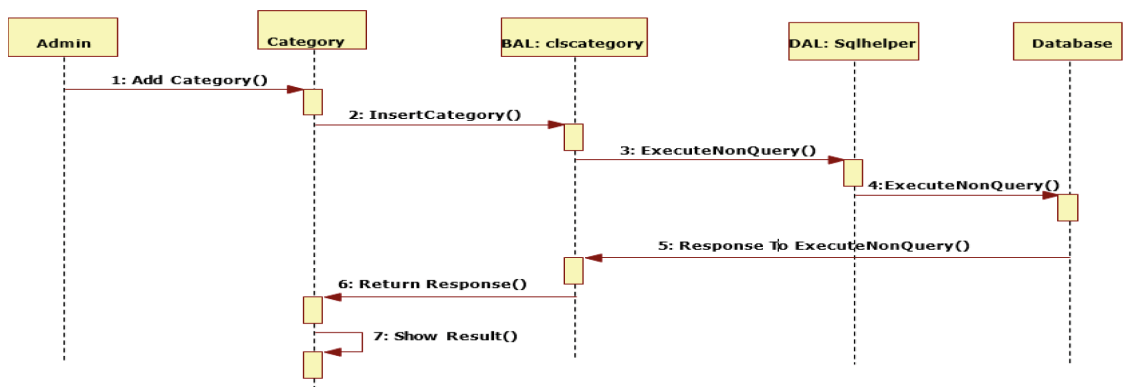

Fig. 5. Admin add category sequence diagram

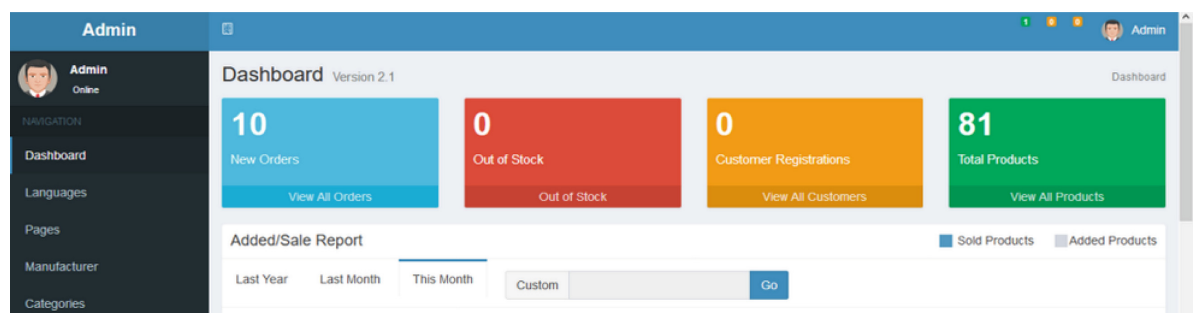

Fig. 6. Admin user dashboard page

\begin{tabular}{|c|c|c|c|c|c|c|}
\hline Admin & \multicolumn{5}{|l|}{ to } & (D) Admin \\
\hline 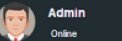 & \multicolumn{5}{|c|}{ Orders Listing All Orders. } & Dashboard - orders \\
\hline MENCATON & \multicolumn{6}{|c|}{ Listing All Orders } \\
\hline Dashboard & 10 & Customer Name & Order Total & Date Purchased & status & Action \\
\hline Languages & 11 & Jjsjs Jss & $\# 1980.00$ & 11/12/2017 & Pendang & -- \\
\hline Pages & 10 & Test lonicecommerce & $=281.35$ & 081092017 & Completed & -- \\
\hline Manutacturer & 9 & Test lonicecommerce & $\$ 281.35$ & 08/09/2017 & Pending & - \\
\hline & 8 & Test Ionicecommerce & $\$ 261.35$ & $08109 / 2017$ & Pending & - \\
\hline Categones & 7 & Test Ionicecommerce & $\$ 299.60$ & 070922017 & Fending & -- \\
\hline Products & 6 & Test lonicecommerce & $\$ 299.60$ & 07/09/2017 & Fend & - \\
\hline News & 5 & Test lonicecommerce & $=299.60$ & 07109/2017 & Fentin & -- \\
\hline Customers & 4 & Test lonicecommerce & $=299.60$ & 07109/2017 & Pending & -- \\
\hline
\end{tabular}

Fig. 7. Listing order page

Figure 6 outline the Admin-User dashboard page: part of the backend module to view every activity from the aspect of ordered products to the order management, user management, and mobile application management and so on. The listing order page, Fig. 7, is the module used to view new ordered products, processed products and processing products. Also, on this page, administrators can manage order status. Sample cart and shopping market place are shown in Fig. 8. Readers should note that due to paper length constraint, several application interfaces are not included. 

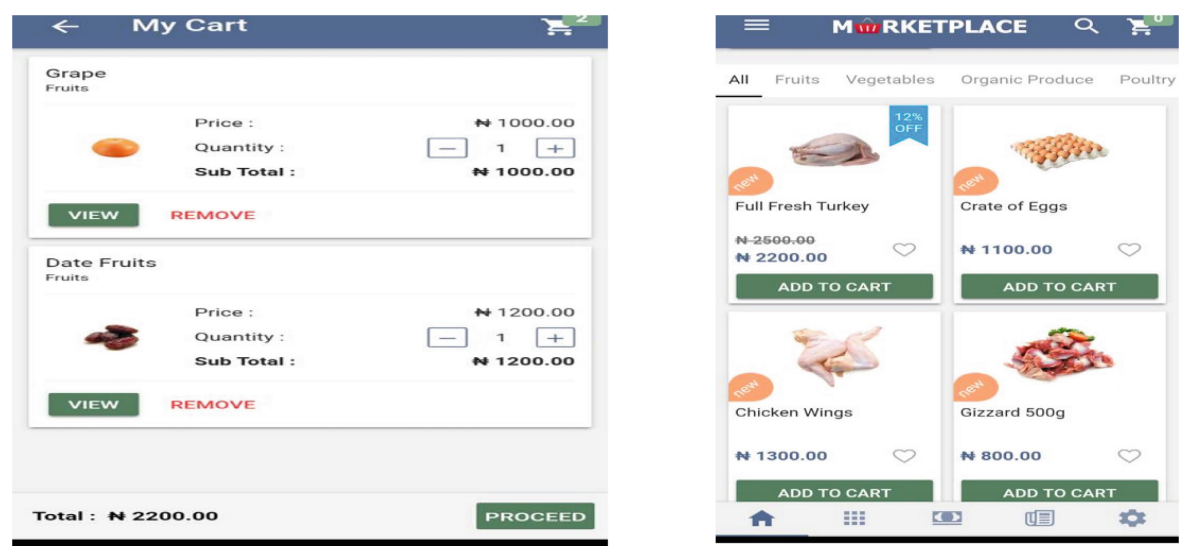

Fig. 8. Sample Cart and shopping market place pages

\section{Conclusion}

This study was carried out through source of opinions from professionals in organic agriculture, literature review, some web materials, survey of organic farmers (primarily in Nigeria), and personal interview of organic farming practitioners.

Orgfarmob marketspace is a mobile application that helps in the process of Buying and Selling of Organic products, gives them access to e-commerce platform and gives them information about the registered cooperative bodies based on geolocation and the aspect of organic farm produce. The system was model with UML.

The main contribution to knowledge of this project is the framework for computer research approach to the conceptualisation and design of real-time, geo-location information delivery system that enables practicing organic farmers to empower themselves and leverage on economics of scale. It provides organic farmers cultivating crops with an e-commerce platform for easy facilitation of their business. It enables practicing organic farmers form a cluster around themselves thereby empowering themselves with the benefits that comes with economics of scale.

\subsection{Future Direction}

In future iteration, usability, acceptance and observation studies are planned. This will be followed by longitudinal studies over a three-to-five years period. Economic consideration might be considered: contingent valuation, hedonic pricing. The authors hope to develop a reference ontology, based on the architectural framework, to assist body of knowledge in the use of mobile application in organic farming. 


\section{References}

1. Zhang, L., Yan, C., Guo, Q., Zhang, J., Ruiz-Menjivar, J.: The impact of agricultural chemical inputs on environment: global evidence from informetrics analysis and visualization. Int. J. Low-Carbon Technol. 13, 338-352 (2018). https://doi.org/10.1093/ijlct/cty039

2. Binta, B.A.A., Barbier, B.: Economic and environmental performances of organic farming system compared to conventional farming system: a case farm model to simulate the horticultural sector of the Niayes region in Senegal. J. Hortic 02, 1-10 (2015). https://doi. org/10.4172/2376-0354.1000152

3. Cioloş, D., Piebalgs, A.: Sustainable agriculture for the future we want. Eur. Commiss. Agric. Rural Dev. (2012)

4. Rockström, J., et al.: A safe operating space for humanity. Nature 461, 472-475 (2009). https://doi.org/10.1038/461472a

5. Campbell, B.M., et al.: Agriculture production as a major driver of the earth system exceeding planetary boundaries. Ecol. Soc. 22, 8 (2017). https://doi.org/10.5751/ES-09595220408

6. Foley, J.A., et al.: Solutions for a cultivated planet. Nature 478, 337-342 (2011). https://doi. org/10.1038/nature10452

7. Nandi, R., Bokelmanna, W., Nithya, V.G., Dias, G.: Smallholder organic farmer's attitudes, objectives and barriers towards production of organic fruits and vegetables in India: a multivariate analysis. Emirates J. Food Agric. 27, 396-406 (2015). https://doi.org/10.9755/ ejfa.2015.04.038

8. Rana, S., Hasan, M.H., Alam, M.S., Islam, M.S.: Farmer attitude towards organic vegetable cultivation in Rangunia Upazila, Chittagong, Bangladesh. J. Biosci. Agric. Res. 14, 11511156 (2017). https://doi.org/10.18801/jbar.140117.141

9. Torres, J., Valera, D., Belmonte, L., Herrero-Sánchez, C.: Economic and social sustainability through organic agriculture: study of the restructuring of the citrus sector in the "Bajo Andarax" district (Spain). Sustainability 8, 918 (2016). https://doi.org/10.3390/su8090918

10. Ton, P.: Productivity and profitability of organic farming systems in East Africa. IFOAM OSEA Proj. 1-60 (2013)

11. Banjara, R.K., Paudel, M.: Economic impact of organic farming; cases from the farmers of Nepal. Adv. Soc. Sci. Res. J. 2, 187-194 (2015). https://doi.org/10.14738/assrj.211.1617

12. Shafie, F.A., Rennie, D.: Consumer perceptions towards organic food. Procedia - Soc. Behav. Sci. 49, 360-367 (2012). https://doi.org/10.1016/j.sbspro.2012.07.034

13. Wang, X., Pacho, F., Liu, J., Kajungiro, R.: Factors influencing organic food purchase intention in developing countries and the moderating role of knowledge. Sustainability 11, 209 (2019). https://doi.org/10.3390/su11010209

14. Lucas, M.R., et al.: Quality, Safety and Consumer Behaviour Towards Organic Food in Germany and Portugal (2008)

15. Monaco, E.: Consumers Buy Organic Food for Taste and Health Reasons, Not Ethics, Study Shows. https://www.organicauthority.com/buzz-news/study-shows-consumers-buy-organicfood-for-taste-and-health-reasons-not-ethics. Accessed 15 Dec 2019

16. Chiciudean, G., Harun, R., Ilea, M., Chiciudean, D., Arion, F., Ilies, G., Muresan, I.: Organic food consumers and purchase intention: a case study in Romania. Agronomy 9, 145 (2019). https://doi.org/10.3390/agronomy9030145

17. Gschwandtner, A.: The organic food premium: a local assessment in the UK. Int. J. Econ. Bus. 25, 313-338 (2018). https://doi.org/10.1080/13571516.2017.1389842 
18. Lee, W.J., Shimizu, M., Kniffin, K.M., Wansink, B.: You taste what you see: do organic labels bias taste perceptions? Food Qual. Prefer. 29, 33-39 (2013). https://doi.org/10.1016/j. foodqual.2013.01.010

19. Lee, M., Hwang, J., Yoe, H.: Agricultural production system based on IoT. In: 2013 IEEE 16th International Conference on Computational Science and Engineering, pp. 833-837. IEEE (2013). https://doi.org/10.1109/CSE.2013.126

20. Meemken, E.-M., Qaim, M.: Organic agriculture, food security, and the environment. Annu. Rev. Resour. Econ. 10, 39-63 (2018). https://doi.org/10.1146/annurev-resource-100517023252

21. Beach, J.: Organic Farming in Maine (2011)

22. Salampasis, M., Theodoridis, A.: Information and communication technology in agricultural development. Procedia Technol. 8, 1-3 (2013). https://doi.org/10.1016/j.protcy.2013.11.001

23. Chavula, H.K.: The role of ICTs in agricultural production in Africa. J. Dev. Agric. Econ. 6, 279-289 (2014). https://doi.org/10.5897/JDAE2013.0517

24. Kiambi, D.: The use of information communication and technology in advancement of African agriculture. Afr. J. Agric. Res. 13, 2025-2036 (2018). https://doi.org/10.5897/ AJAR2018.13300

25. Saidu, A., Clarkson, A.M., Adamu, S.H., Mohammed, M., Jibo, I.: Application of ICT in agriculture: opportunities and challenges in developing countries. Int. J. Comput. Sci. Math. Theory. 3, 8-18 (2017)

26. Hamzaoui-Essoussi, L., Zahaf, M.: The organic food market: opportunities and challenges. In: Reed, M. (ed.) Organic Food and Agriculture - New Trends and Developments in the Social Sciences. InTech (2012). https://doi.org/10.5772/30155

27. Saunders, M.N.K., Lewis, P., Thornhill, A.: Understanding research philosophy and approaches to theory development. In: Research Methods for Business Students, pp. 128170. Pearson, Harlow (2019)

28. Amaral, J.N., et al.: About Computing Science Research Methodology. Edmonton, Alberta, Canada (2011). https://doi.org/10.1.1.124.702

29. Holz, H.J., Applin, A., Haberman, B., Joyce, D., Purchase, H., Reed, C.: Research methods in computing. In: Working Group Reports on ITiCSE on Innovation and Technology in Computer Science Education - ITiCSE-WGR 2006, p. 96. ACM Press, New York (2006). https://doi.org/10.1145/1189215.1189180

30. Alwadain, A.S.A.: A model of enterprise architecture evolution (2014). http://eprints.qut. edu.au/71204/ 